This item was submitted to Loughborough's Research Repository by the author.

Items in Figshare are protected by copyright, with all rights reserved, unless otherwise indicated.

\title{
Information efficiency changes following FTSE 100 index revisions
}

PLEASE CITE THE PUBLISHED VERSION

http://dx.doi.org/10.1016/j.intfin.2012.01.002

\section{PUBLISHER}

(c) Elsevier B.V.

\section{VERSION}

AM (Accepted Manuscript)

\section{LICENCE}

CC BY-NC-ND 4.0

\section{REPOSITORY RECORD}

Daya, Wael, Khelifa Mazouz, and Mark Freeman. 2019. "Information Efficiency Changes Following FTSE 100 Index Revisions". figshare. https://hdl.handle.net/2134/15026. 
This item was submitted to Loughborough's Institutional Repository (https://dspace.lboro.ac.uk/) by the author and is made available under the following Creative Commons Licence conditions.

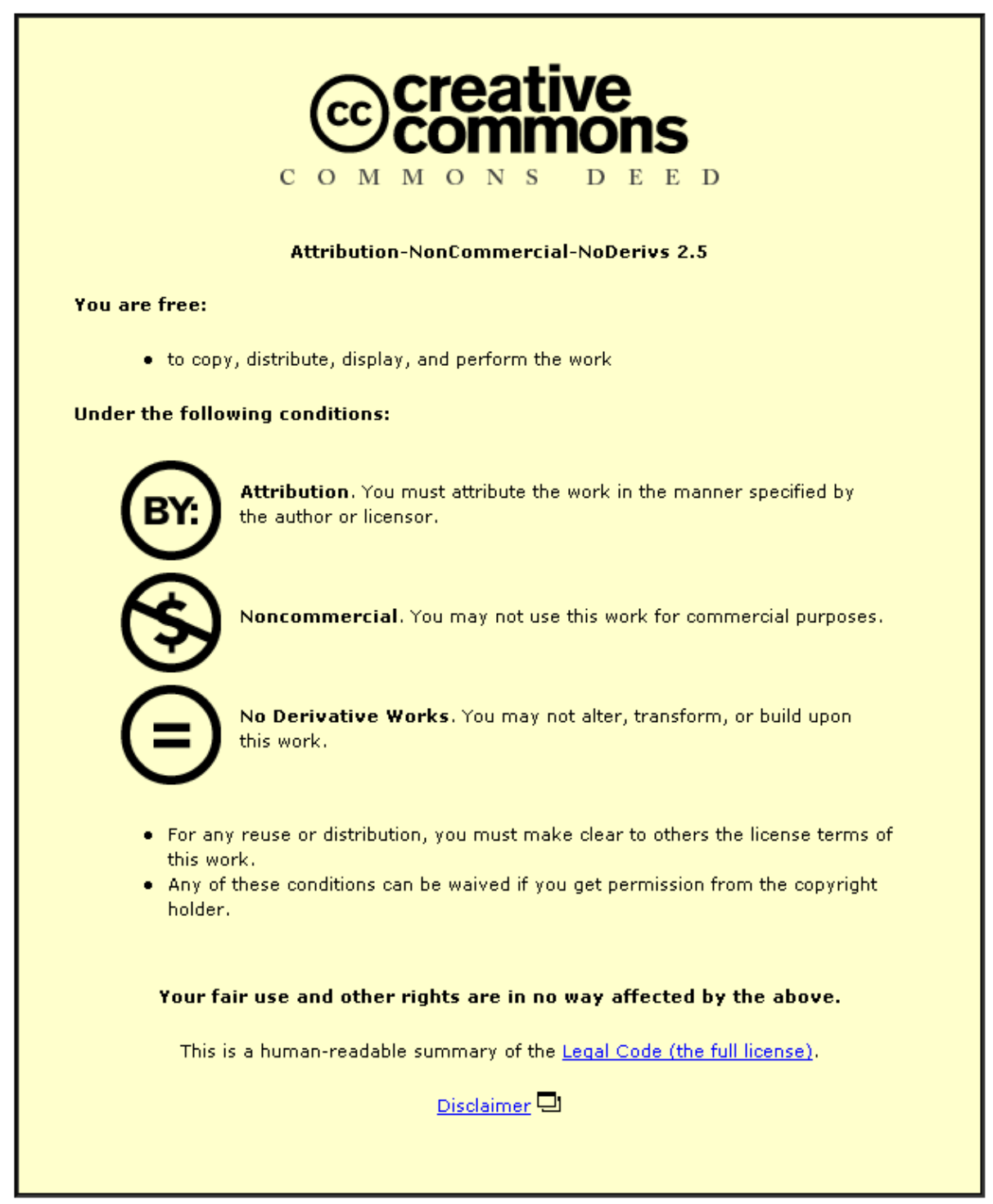

For the full text of this licence, please go to: http://creativecommons.org/licenses/by-nc-nd/2.5/ 


\title{
Information efficiency changes following FTSE 100 index revisions
}

\author{
Wael Daya ${ }^{\mathrm{a}}$, Khelifa Mazouz ${ }^{\mathrm{a},{ }^{*}}$ and Mark Freeman ${ }^{\mathrm{a}}$ \\ ${ }^{a}$ Bradford University School of Management, Emm Lane, Bradford, BD9 4JL, UK
}

\begin{abstract}
This study examines the impact of FTSE 100 index revisions on the informational efficiency of the underlying stocks. Our study spans the 1986-2009 period. We estimate the speed of price adjustment and price inefficiency from the partial adjustment with noise model of Amihud and Mendelson (1987). We report a significant improvement (no change) in the informational efficiency of the stocks added to (deleted from) the FTSE 100 index. The asymmetric effect of additions and deletions on the informational efficiency can be attributed, at least partly, to certain aspects of liquidity and other fundamental characteristics, which improve following additions but do not diminish after deletions. Cross-sectional analysis also indicates that stocks with low pre-addition market quality benefit more from joining the index.
\end{abstract}

JEL classification: G15

Keywords: Index revisions; market quality; liquidity; idiosyncratic risk

*Corresponding author:

Email: k.mazouz@bradford.ac.uk; Telephone: +44(0) 1274234349

\section{Acknowledgments}

We are grateful to the comments of an anonymous referee and the editor that have considerably enhanced the paper. 


\section{Introduction}

This study examines the impact of FTSE 100 index revisions on the informational efficiency of the underlying stocks. It contributes to the literature in three important ways. First, while previous literature consistently finds that there are price gains, increases in investor awareness, and long-term improvements in stock liquidity following additions, this paper proposes a new approach to consider in detail whether index members also benefits from greater informational efficiency. Second, while most literature finds that, when a firm is removed from a major stock index, it experiences both stock price and liquidity falls, there are some studies that report that the advantages of gaining membership remain even after removal from the index. We extend this debate by examining whether the informational efficiency of a stock is reduced after removal from the index. Finally, we are able to explain the key determinants of informational efficiency changes around the time of joining and leaving the membership of the index.

Using data from 1986 - 2009 to test whether FTSE 100 index revisions affect the market quality of stocks, we compare two measures of informational efficiency before and after index revisions. First, we use the Amihud and Mendelson (1987) technique to estimate the speed at which information is incorporated into the stock price. We then use the price inefficiency index developed by Chelley-Steeley (2008) to capture the degree to which the stock price deviates from its intrinsic value. We use a control sample to ensure that our results are not driven by factors other than the index revisions and then conduct cross-sectional analysis to identify the main determinants of the informational efficiency changes.

We find that the informational efficiency of a stock added to the FTSE 100 index is improved. However, deletions do not exhibit any significant changes in the speed of price adjustment or pricing inefficiency. The asymmetric response of market quality to additions and deletions can partly be attributed to certain aspects of liquidity and other fundamental characteristics, which improve following additions, but do not always diminish after deletions. This result is also consistent with Chen et al. (2004) who show that investors' awareness increases when a stock joins the S\&P 500, but does not decrease following its deletion from the index. Our cross-sectional analysis indicates that stocks with low preaddition informational efficiency benefit more from joining the index. This evidence is in line with Roll et al.'s (2009) finding that information production following options listing is larger in stocks where information asymmetries are the greatest. Our cross-sectional results also suggest that changes in informational efficiency are significantly related to changes in the information environment, idiosyncratic risk, liquidity and book-to-market value.

The remainder of the paper is organized as follows. Section 2 provides a brief review of the related literature and states the hypotheses to be tested. Section 3 presents the methodology. Section 4 describes our data. Section 5 presents and discusses the empirical findings and Section 5 concludes. 


\section{Literature review and hypothesis development}

Since Dhillon and Johnson (1991) first reported stock price increases following additions to the S\&P 500, academic studies have consistently found that firms benefit from joining major stock market indices. Index tracker funds need to rebalance their portfolios, leading to increased demand for the newly included stock. There is also evidence that inclusion, by itself, is perceived by the market as being an intrinsic measure of quality (for example, Denis et al., 2003; Sui, 2003; and Chakrabarti, 2002). Cai (2007) claims that S\&P 500 index additions may convey new information to the market for two reasons. First, when a firm is added to the index, the Index Membership Committee certifies it as a leading firm. Second, because of the high turnover caused by index fund managers rebalancing their portfolios, certain Index Membership Committees may select firms that are likely to meet the index criteria for longer periods of time.

There are also clear long-term benefits in terms of liquidity and market awareness from inclusion in major stock market indices. Chen et al. $(2004$, 2006) find that investors become more aware of a stock upon its addition to the S\&P 500 index and that the number of individual shareholders increases when a stock joins the index. Hacibedel (2008) demonstrates that there is a considerable increase in analysts' coverage for new members of the MSCI index. Sofianos (1993) argues that index arbitrage may involve small and frequent trading. The enhanced trading frequency may reduce the inventory risk of market markers and hence enhance liquidity. Hegde and McDermott (2003) also attribute the price effects associated with S\&P 500 revisions to liquidity changes in the post-revision period. Chakrabarti et al. (2005) show that trading volume rises after additions in a large number of major world stock markets, but not the US. In the case of the London stock market, Mazouz and Saadouni (2007) attribute the price patterns following FTSE 100 index revisions to non-information-related liquidity effects.

Because of these rebalancing, informational and liquidity effects, it is accepted that stock prices rise when a company is included in a major index. The main point of contention is whether this price rise is a permanent or transitory effect. The informational and liquidity arguments suggest that the effect should be permanent, while the rebalancing effect is temporary. Shleifer (1986) and Lynch and Mendenhall (1997) show that stocks experience permanent price increases on the announcement of their inclusion to the S\&P 500 index. Deininger et al. (2000) find that stocks added to the German blue-chip index, the DAX, and the mid-cap index, the MDAX, experience permanent price increases. Chakrabarti et al. (2005) show that stocks from the UK, Japan, and emerging markets experience permanent price changes following index revisions. However, Harris and Gurel (1986) show that stock prices increase following announced additions to the S\&P 500, but these effects are fully reversed after two weeks. Pruitt and Wei (1989) argue that temporary price changes following index revisions are consistent with heavy index-fund trading around the time of the change that move stock prices away from their equilibrium values. Chung and Kryzanowski (1998), Elayan et al. (2000), Rigamonti and Barontini (2000), Shankar and Miller (2006), and Daniel and Gerard (2007) also observe temporary price increases following 
additions to the Toronto Stock Exchange (TSE 300), the New Zealand Stock Exchange (NZE10 and NZSE40), the Italian Stock Exchange (Mib30), the S\&P Small-Cap 600, and the Australian Stock Exchange (ASX200), respectively. In the context of the London Stock Exchange, Mase (2007) shows that stock prices increase gradually before the announcement of an inclusion and reverse completely in less than two weeks after the index revision date, while Mazouz and Saadouni (2007) find permanent price effects.

The evidence on whether removal from index membership adversely affects liquidity, market awareness and stock prices is more ambiguous. For example, Chen et al. $(2004,2006)$ find that investors do not become unaware of a stock following its deletion, and that both the extent of media coverage and the number of individual shareholders are also not affected by index deletions. Chakrabarti et al. (2005) show that, while in many international markets trading volume decreases after index deletions, this is not the case for either the US or the UK. However, a large majority of studies that report temporary price rises in the case of additions also report temporary price declines in the case of deletions.

This evidence leads us to formulate testable hypotheses for market efficiency around the time of inclusion and exclusion from the membership of a major market index. If there is increased liquidity, trading volume and market awareness around the time of inclusion in an index, then we hypothesise that informational efficiency will increase. Similarly, we would hypothesise that changes in efficiency to additions and deletions will only be symmetric if the core underlying variables, such as market liquidity, also change in a symmetric way. We test these hypotheses by examining changes to the constituents list of the FTSE 100 index, which represents approximately 80\% (9\%) of the UK's (the world's) equity.

The FTSE Steering Committee is in charge of conducting a quarterly review of the FTSE 100 constituents list. Stocks listed on the London Stock Exchange are ranked by their market capitalization at the close of business on the day before the index revisions. Any company in the FTSE 100 list falling to 111th position or below will be automatically deleted from the index, while any company rising to 90th position or above will be automatically added to the index. To ensure that the index always maintains exactly 100 members, the highest (lowest) market capitalization stocks outside (inside) the index are added (removed) if the number of automatic deletions exceeds (is less than) the number of automatic inclusions. ${ }^{1}$ Any constituent change is implemented on the third Friday of the same month, so that there are currently seven working days between the announcement and effective change dates.

\footnotetext{
${ }^{1}$ A detailed description of the construction of the FTSE 100 index can be found in the Ground Rules for the Management of the UK Series of the FTSE Actuaries Share Indices

http://www.ftse.com/Indices/UK_Indices/Downloads/FTSE_UK_Index_Series_Index_Rules.pdf; accessed 20 May 2011).
} 


\section{Methodology}

\subsection{Informational efficiency measures}

Amihud and Mendelson (1987) propose a model that distinguishes between a security's intrinsic value and its observed price. They attribute this difference to noise (see also Black, 1986). Their model is specified as follows

$$
\begin{aligned}
& \mathrm{p}_{\mathrm{t}}-\mathrm{p}_{\mathrm{t}-1}=\mathrm{g} \cdot\left[\mathrm{v}_{\mathrm{t}}-\mathrm{p}_{\mathrm{t}-1}\right]+\mathrm{u}_{\mathrm{t}}, \\
& 2>g>0 \quad E\left(\mathrm{u}_{\mathrm{t}}\right)=0 \quad \operatorname{Var}\left(\mathrm{u}_{\mathrm{t}}\right)=\sigma_{\mathrm{u}}^{2},
\end{aligned}
$$

where $p_{t}$ is the logarithm of the observed prices $P_{\mathrm{t}}, \mathrm{v}_{\mathrm{t}}$ is the logarithm of the intrinsic value $V_{\mathrm{t}}, g$ is the price adjustment parameter, reflecting the speed at which information is incorporated into the stock price, and $\mathrm{u}_{\mathrm{t}}$ is white noise, which temporarily pushes the observed price away from its intrinsic value. Amihud and Mendelson argue that noise can be induced by: (i) noise traders, who trade merely to satisfy their transitory liquidity needs; (ii) errors in the analysis and interpretation of information or (iii) the trading mechanisms by which prices are set in the market.

Amihud and Mendelson assume that the logarithm of intrinsic value, $v_{t}$, follows a random walk process with drift

$$
v_{t}=m+v_{t-1}+e_{t}
$$

where $m$ is the positive drift, $e_{t}$ is a random error, independent of $\mathrm{u}_{\mathrm{t}}$, with zero mean and finite variance, $\sigma_{v}^{2}$

\subsubsection{The partial adjustment process}

The coefficient $g$ reflects the speed at which transaction prices covert back to their true values. In particular, $g=0$ represents the extreme case of no price adjustment back to efficiency, $0<g<1$ implies partial price adjustment, $g=1$ suggests full price adjustment, and $g>1$ indicates that the observed prices over-adjusts. The magnitude of partial price adjustment is determined by the amount and quality of information as well as the extent to which markets are efficient. Thus, examining the change in the parameter $g$ between pre- and post-addition (deletion) periods, allows us to gauge whether FTSE 100 index revisions affect the price discovery process. If inclusion to (exclusion from) the FTSE 100 index improves (reduces) informational efficiency, the parameter $g$ of the added (deleted) stocks should move closer to (deviate further from) unity. 


\subsubsection{Price inefficiency}

Chelley-Steeley (2008) defines pricing inefficiency $\left(p i_{t}\right)$ as the absolute value of the difference between the observed price $\left(\mathrm{p}_{\mathrm{t}}\right)$ and its intrinsic value $\left(\mathrm{v}_{\mathrm{t}}\right)$, or

$$
\mathrm{pi}=\left|\mathrm{v}_{\mathrm{t}}-\mathrm{p}_{\mathrm{t}}\right|
$$

The mean pricing error $\left(\mathrm{PI}_{\mathrm{T}}\right)$ over a given time period $[1, T]$ is given as follows

$$
\mathrm{PI}_{\mathrm{T}}=\sum_{\mathrm{t}=1}^{\mathrm{T}} \frac{\mathrm{pi}_{\mathrm{t}}}{\mathrm{T}}
$$

An improvement in market quality is associated with a decline in $P I_{\mathrm{T}}$. Hence, if inclusion to (exclusion from) the FTSE 100 index enhances (harms) informational efficiency, one should observe a decrease (an increase) in $P I_{\mathrm{T}}$ following additions (deletions).

\subsection{Estimation method}

Lyhagen (1999) shows that the price adjustment coefficient model of Amihud and Mendelson (1987) can be estimated using a Kalman filter. They also show that the Kalman filter process is much more efficient than other traditional techniques, such as Moving Average Convergence Divergence $(M A C D)$, Autoregressive Moving Average (ARMA), and a Logistic Binary Estimation (LOGIT). Similar evidence is reported by Brooks et al., (1998), Faff et al., (2000) and Dunis and Morrison (2007). Thus, we use the Kalman filter technique to estimate the unobserved true price from the observed price and decompose a contaminated price into a true price and noise. ${ }^{2}$

The filtering process includes a set of equations which allow an estimator to be updated once a new observation becomes available. This process is carried out in two steps. The first step consists of forming the optimal predictor of the next observation, based on currently available information. In the second step, the new observation is incorporated into the estimator of the state vector using the updating equation (Harvey, 1991). These two steps can formally be presented as follows

$$
\begin{cases}\text { Measurement equation } \quad Y_{t}=X_{t} B_{t}+d_{t}+\varepsilon_{t} & \mathrm{t}=1, \ldots, \mathrm{T} \\ \text { Transition equation } \quad B_{t}=T_{t} B_{t-1}+c_{t}+R_{t} \eta_{t} & \mathrm{t}=1, \ldots, \mathrm{T},\end{cases}
$$

where $Y_{t}$ is the observed variable at time $\mathrm{t}, X_{t}$ is the vector of explanatory variables at time $t ; \mathrm{B}_{\mathrm{t}}$ and $B_{t-1}$ are state variables at times $\mathrm{t}$ and $\mathrm{t}-1$ respectively; $\varepsilon_{t}$ and $\eta_{t}$ are uncorrelated error terms drawn from a normal distribution with zero mean.

$$
\left\{\begin{aligned}
\varepsilon_{t} & \sim \mathcal{N}\left(0, \sigma_{\mathrm{u}}^{2}\right) \\
\eta_{t} & \sim \mathcal{N}\left(0, \mathrm{~g}^{2} \sigma_{\mathrm{v}}^{2}\right)
\end{aligned}\right.
$$

\footnotetext{
${ }^{2}$ The same estimation approach is used by Chelley-Steeley (2008) in the context of market microstructure.
} 
We use Kalman filtering to estimate the informational efficiency measures as follows

$$
\mathrm{p}_{\mathrm{t}}-\mathrm{p}_{\mathrm{t}-1}=\mathrm{g} \mathrm{v}_{\mathrm{t}}-\mathrm{g} \mathrm{p}_{\mathrm{t}-1}+\mathrm{u}_{\mathrm{t}}
$$

If we set $\mathrm{g} \mathrm{v}_{\mathrm{t}}=\alpha_{\mathrm{t}}$ and $-\mathrm{g}=\mathrm{g}^{*}$ we can write equations (1) and (2) in state space form as follows

$$
\left\{\begin{array}{ll}
\text { Measurement equation } & \mathrm{p}_{\mathrm{t}}-\mathrm{p}_{\mathrm{t}-1}=\alpha_{\mathrm{t}}+\mathrm{g}^{*} \mathrm{p}_{\mathrm{t}-1}+\mathrm{u}_{\mathrm{t}}, \quad \mathrm{u}_{\mathrm{t}} \sim \mathcal{N}\left(0, \sigma_{\mathrm{u}}^{2}\right) \\
\text { Transition equation } \quad \alpha_{\mathrm{t}}=\alpha_{\mathrm{t}-1}+d+\eta_{t}, & \eta_{t} \sim \mathcal{N}\left(0, \mathrm{~g}^{2} \sigma_{\mathrm{v}}^{2}\right)
\end{array}\right. \text {, }
$$

where $\alpha_{t}$ is treated as a time-varying unobservable state variable. Since $v_{t}$ is a random walk with drift, the transition equation describes the unobservable state variable $\alpha_{t}$ through time $t$. The drift term $d$ is the drift of the intrinsic value process scaled by the partial adjustment coefficient and $d=g m$. Since $\eta_{t}$ is the error term in the intrinsic value process scaled by the partial adjustment coefficient, it also has a zero mean and a variance $g^{2} \sigma_{v}^{2}$. The value of $g^{2} \sigma_{v}^{2}$ is unknown and must be estimated. Values of $v_{t}$ are obtained by dividing $\alpha_{t}$ by $g$. Following Chelley-Steeley (2008), we use maximum likelihood methods, with initial parameter estimates obtained from the first two observations in the sample, to estimate the value of the variance $g^{2} \sigma_{v}^{2}$.

We estimate the pre- and post-revision $g$ and $\mathrm{PI}_{\mathrm{T}}$ after excluding a window immediately around the effective index revision dates. We do this for two reasons. First, since the FTSE 100 index revision decisions are based solely on market capitalization, additions and deletions are well anticipated by market participants and stock price changes may occur well before the actual announcement dates (see, e.g. Mase, 2007). Thus, price movements immediately before events may not be representative of the true pre-revision period. Second, due to index funds executing substantial purchases (sales) of the added (deleted) stocks, significant abnormal price movements may be observed during the period immediately after index revision events. Consistent with the price pressure hypothesis, Vespro (2006) and Mase (2007) show that buying and selling pressures around FTSE 100 index revisions move prices temporarily away from their equilibrium values. Thus, including the window immediately after the event may result in biased estimates of post-revision $g$ and $P I^{3}$

In unreported results, we determine which window to exclude by estimating cumulative average abnormal returns (CARs) over several event windows. We find that CARs are statistically significant only in the windows within \pm 30 days around the index revision dates. We therefore estimate the preand post-revision $g$ and $\mathrm{PI}_{\mathrm{T}}$ within the windows $[-261,-31]$ and $[+31,+260] .{ }^{4}$

\footnotetext{
${ }^{3} \mathrm{We}$ are grateful to the anonymous referee from pointing out this issue.

${ }^{4}$ Note that our conclusions remain unchanged when $g$ and $\mathrm{PI}_{\mathrm{T}}$ are estimated over the $[-261,-1]$ and $[+1,+260]$ windows. Further details can be obtained from the authors.
} 
To account for the possible impact of factors other than index revisions on our findings, we use a control sample methodology. We construct our control sample by matching each event stock with a control stock (i) with the closest market capitalization to the event stock at one month before revision; ${ }^{5}$ (ii) that has never been a member of the FTSE 100 index, and (iii) that has a full set of 420 daily price observations available from DataStream.

\section{Data and descriptive statistics}

\subsection{Data}

We identify 367 FTSE 100 index revision events over the period from January 1984 to June 2009. We exclude from our analysis stocks that were added (deleted) due to events such as mergers, spin-offs and takeovers, which are identified using data from different resources, including Thomson One Bank, FT.com and the media coverage of each company.

The effective dates for all quarterly changes are obtained from FTSE International Limited and the DataStream. To be included in the sample, a stock needs to have a complete set of 420 working days around the effective change date. ${ }^{6}$ The final sample includes 432 stock, 212 additions and 210 deletions, including both surviving and dead stocks. We match each event stock with a control stock using the matching procedure described in Section 4.2. Daily data taken from DataStream includes market capitalization, closing price, opening price, trading volume, number of trades, bid-ask spread, book-tomarket value and the number of shares outstanding. Table 1 provides the yearly distribution of additions and deletions across the study period.

\section{[Insert Table 1 about here]}

\subsection{Descriptive statistics}

Table 2 reports descriptive statistics of the event stocks and their control pairs. Panels A summarizes the pre-index revision (i.e. [-261, -31]) characteristics, namely market capitalization $(M V)$, book-to-market value $(B T M V)$, trading volume $(V O)$, number of trades $(N T)$, bid-ask spread (Ask-Bid), illiquidity (Amihud $)^{7}$ and number of zeros in the daily return series (Zeros) of the added stocks and their control pairs. The paired t-test indicates that added stocks and their matched pairs differ significantly in terms of $M V$ and Amihud, reflecting the Steering Committee's decision to include stocks with large $M V$. However, the Mann-Whitney test suggests that the pre-index revision characteristics of the event stocks and their matched pairs belong to the same distribution.

\footnotetext{
${ }^{5}$ Recall that stocks are included to and excluded from the FTSE 100 index solely on the basis of their market capitalization.

${ }^{6}$ The same requirement is used by Liu (2009).

${ }^{7}$ Amihud's illiquidity is measured as $I L L I Q_{t}^{i}=\frac{1}{\operatorname{Days}_{t}^{i}} \sum_{d=1}^{D a y s_{t}^{i}} \frac{\left|R_{t, d}^{i}\right|}{V_{t, d}^{i}}$, where $R_{t, d}^{i}$ and $V_{t, d}^{i}$ are the return and dollar volume on day $\mathrm{d}$ in month t, respectively; Days $t_{t}^{i}$ is the number of valid observation days in month $\mathrm{t}$ for stock $\mathrm{i}$.
} 
Panel B presents the pre-index revision characteristics of the deleted stocks and their matched pairs over the [-261, -31] window. Both t-test and Mann-Whitney test suggest that the mean values of $M V, V O$, and $N T$ are higher for the sample of deleted stocks than the control sample. Furthermore, the pre-deletion values of the illiquidity measures, namely Amihud and Zeros, are lower for the sample of deleted stocks than the control sample. However, the deleted stocks do not differ significantly from their control pairs in terms of BTMV and Ask-Bid, implying that the two samples share some important common pre-deletion characteristics.

Table 3 reports the changes, across pre- and post-index revision periods, for $M V, B T M V, V a r, V O$, NT, Ask-Bid, Amihud, Zeros, and Lexis/Nexis ${ }^{8}$ associated with additions and deletions. The results indicate that, with the exception of idiosyncratic risk, which is measured as the variance of the residual error of the market model, and Var, liquidity proxies, common risk factors and the information environment improve following additions to the FTSE 100 index. It also shows that apart from $M V$ and liquidity (measured by Zeros, Amihud and Ask-Bid), the rest of the variables remain largely unchanged after deletions.

\section{[Insert Table 3 about here]}

\section{Empirical Results}

\subsection{Market quality changes following additions}

Table 4 reports the informational efficiency parameters associated with the pre- and post-index revision periods. Panels A and B present the average speed of price adjustment parameter $(g)$ and price inefficiency measure $\left(\mathrm{PI}_{\mathrm{T}}\right)$ associated with additions over the 1986-2009 period respectively. Panel A shows the mean (median) $g$ moves significantly towards unity, from 0.924 to 0.966 (0.907 to 0.959 ), between the pre- and post-addition periods, with approximately $63 \%$ of the stocks experiencing a rise in the price adjustment parameter when they enter the FTSE 100 index. This finding indicates that a stock's informational efficiency improves when it joins the index. This result is unlikely to be driven by factors other than index revisions, as the control stocks do not experience any significant change in $g$ between the pre- and post-addition periods.

\footnotetext{
${ }^{8}$ We obtain data for press coverage through systematic manual searches in Lexis/Nexis. Following Liu (2009), for each firm in each sample, we search for the number of "Business News" (news category) items from "Business \& Finance" sources (news source) in the search domain in the prior and posterior one-year periods separately. We measure press coverage by the number of times that the name of a stock appears in the "Headline, Lead Paragraph(s), or Terms" of news articles in a given search period. This default search domain is intended to ensure adequate data availability, while avoiding trivial report that occurs in passing. If the number of appearances for a stock exceeds 1000 in the default search domain within a search period and the search is interrupted by default, we then limit the scope of the search for the stock to "Headline" alone in all search periods employed to ensure comparability. This more restrictive search domain approach applied to all stocks added to the FTSE 100 index.
} 


\section{[Insert Table 4 about here]}

Panel B shows that the mean (median) $\mathrm{PI}_{\mathrm{T}}$ decreases significantly from 1.988 (1.613) in the preaddition period to 1.705 (1.316) in the post-addition period, with $56 \%$ of event stocks experiencing a decline in $\mathrm{PI}_{\mathrm{T}}$. Again, the control sample does not exhibit any significant changes in the mean $\mathrm{PI}_{\mathrm{T}}$ between the pre- and post-addition periods. The finding that transaction prices move closer to their intrinsic values after additions also suggests that the market quality of the underlying stocks improve when they become members of the FTSE 100 index.

\subsection{Market quality changes following deletions}

Table 5 reports the mean (median) $g$ and $\mathrm{PI}_{\mathrm{T}}$ of the main and control stocks in the pre- and postdeletion periods. Panel A shows that the mean (median) partial adjustment coefficient drops from 0.948 (0.936) to 0.939 (0.935) following deletions, with approximately $46 \%$ of the stocks experiencing a decrease in their parameter $g$ after deletion. However, both the standard t-test and the Wilcoxon Signed rank test indicate the observed post-deletion decline in $g$ is not statistically significant. In contrast, Panel A reports that the mean (median) $g$ associated with the control stocks increases from $0.918(0.905)$ in the pre-deletion period to 0.936 (0.934) in post-deletion period. The paired t-test, but not the Wilcoxon Signed rank test, indicates that the deleted stocks and their control pairs exhibit significantly different average $g$ changes across pre- and post-deletion periods.

\section{[Insert Table 5 about here]}

Panel B shows that the post-deletion increase in the mean $\mathrm{PI}_{\mathrm{T}}$ is also not statistically significant. The mean $\mathrm{PI}_{\mathrm{T}}$ only decreases in $46 \%$ of the deletion cases. The paired t-test shows that the change in the pricing inefficiency associated with the control sample is also not significantly different from zero, while a weak level of significance is detected by the Wilcoxon Signed rank test.

Thus, our results indicate that the market quality improves after additions, but does not deteriorate following deletions. This asymmetry is consistent with the investor awareness view of Chen et al. (2006), which suggests that investor awareness increases when a stock enters into the index, but does not fall when a stock leaves the index

\subsection{Cross-sectional analysis}


Our previous findings suggest that stocks experience significant improvements in their market quality after joining the FSTE 100 index. ${ }^{9}$ To examine the determinants of the change in market quality after a stock joins the index, we regress $\Delta g$ and $\Delta \mathrm{PI}_{\mathrm{T}}$ against their pre-addition values and different combinations of the following set of explanatory variables; the change in trading volume $(\triangle V O)$, the change in the number of trades $(\Delta N T)$, the change in illiquidity ( $\triangle A$ mihud), the change in the bid-ask spread $(\Delta A s k-B i d)$, the change in the non-trading $(\Delta$ Zeros $)$, the change in media coverage $(\Delta$ Lexis / Nexis), the change in firm size $(\triangle M V)$, the change in book-to-market value $(\triangle B T M V)$, and the change in the residual variance of returns $(\Delta \mathrm{VAR}) .{ }^{10} \mathrm{We}$ include the pre-additions market quality measures in the regressions to test whether stocks with low pre-addition market quality benefit more from joining the index. ${ }^{11}$ We provide justifications for the other explanatory variables below.

\subsubsection{The determinants of market quality changes}

Previous studies (e.g. Easley and O'Hara, 1987; Grossman and Miller, 1988; Bacidore, 1997; Madhavan et al., 2005; Lu and Hwang, 2007) relate market quality changes to changes in the information environment, idiosyncratic risk, liquidity and other fundamental characteristics of the firm.

\subsubsection{Changes in stock liquidity}

Existing studies propose several liquidity measures. Trading volume, numbers of trades, and transaction costs are amongst the most widely used proxies for liquidity and investor's attention. Easly and O'Hara (1987) show that high trading volume affects the speed rate of price adjustment. They find stock prices adjust more slowly to large trades than small trades. Chordia and Swaminathan (2000) show that low volume stocks respond more slowly to market-wide information than high volume stocks. Hauser et al. (2001) report that increased volume and number of trades per session reduce the aggregate pricing error and related returns volatility. Ali et al. (2003) argue that securities with higher transaction costs are more likely to exhibit greater residual mispricing. Mech (1993) attributes the speed of the price adjustment process to non-trading (i.e. Zeros) while Lesmond et al., (1999) conclude that Zeros result from transaction costs.

Reflecting on the above arguments, we use $\Delta V O, \Delta N T, \triangle A m i h u d, \Delta A s k$-Bid as explanatory variables in our cross-sectional regressions.

\subsubsection{Changes in common risk factors}

Fama and French (1992) consider market capitalization and book-to-market value as proxies for common risk factors. As discussed earlier in this study, market capitalizationis a major factor in FTSE

\footnotetext{
${ }^{9}$ Cross-sectional analysis is conducted only on additions, as deletions do not exhibit any consistent statistically significant changes in $g$ or $\mathrm{PI}_{\mathrm{T}}$.

${ }^{10}$ Recall that the change is measured between the $[-261,-31]$ and the $[+31,+260]$ windows around the index revision dates.

${ }^{11}$ Roll et al. (2009) suggest that information production following option listing is larger in stock where information asymmetries are greater and where investment analysis produces comparatively less public information.
} 
100 index revision decisions. Given this, a legitimate concern regarding the efficiency effect reported above is that it may simply be a market value effect. Damodaran (1993) examines the relationship between stock market value and the speed of price adjustment. The result shows that the portfolio with the greatest market value adjusts to new information faster than small market value portfolios. Hasbrouck (1993) finds that pricing errors are negatively related to market value. Several researchers, including Chan and Faff (2005), Chen and Zhang (1998) and Lu and Hwang (2007), also show that stocks with high book to market value, small market size, and low analyst coverage are likely to be mispriced.

This provides strong justification for the inclusion of $\triangle M V$ and $\triangle B T M V$ in our cross-sectional regressions.

\subsubsection{Changes in idiosyncratic risk}

Bhagat et al. (1985) report a positive association between issuing cost and idiosyncratic risk, which reflects the asymmetric information between firm insiders and outsiders. Similarly, Easley and O'Hara (1987), De Long et al. (1990) and Huang and Masulis (2003) show that idiosyncratic risk is positively associated with the size of trade. They argue that large trades exhibit a greater adverse selection

effect, as they are executed by better-informed investors. Kelly (2005) also shows that high idiosyncratic risk is associated with a poor information environment with greater noise trading, which causes stock prices to deviate from their fundamental values. However, Durnev et al. (2003) find that firms and industries with greater idiosyncratic volatility display greater stock price informativeness. They argue that if idiosyncratic volatility reflects the capitalization of private information into prices, high idiosyncratic volatility is a sign of active trading by informed arbitrageurs and implies that the stock price is tracking its fundamental value closely.

To capture the potential impact of changing idiosyncratic risk on the market quality of the underlying stocks, we include the change in the residual variance of the market model $(\triangle V A R)$ as an explanatory variable in our cross-sectional regression.

\subsubsection{Changes in information environment}

Shleifer (1986) argues that index membership attracts more media, stock analysts and institutional investors. Accordingly, more information should be generated and incorporated into the prices of the added stocks. Jennings and Starks (1985) find that stocks with better earnings reports are associated with high investor perceptions and greater information content. Thus, the speed of price adjustment is faster for stocks with better information. Bhushan (1989) finds that the information environment, measured by the number of analysts, is positively associated with the speed of adjustment. In addition, and ceteris paribus, the aggregate demand for analyst services is likely to be an increasing function of firm size. An investor is likely to find a piece of private information about a larger firm more valuable than the same piece of information about a smaller firm. Liu (2009) investigates reshuffles of the Nikkei 225 and shows that 
changes in press coverage for additions and deletions are consistent with the notion that Nikkei 225 membership attracts more press coverage, which generates more information about the added stocks.

To account for the impact of changes in the information environment on our results, we include $\Delta$ Lexis/Nexis as one of the explanatory variables in the cross-sectional regressions.

\subsubsection{Correlations}

Table 6 presents correlations among the changes in the dependent and explanatory variables. The changes in both explanatory and dependent variables are calculated as the difference between the postand pre- addition periods. Table 6 shows that $\Delta g$ and $\Delta \mathrm{PI}_{\mathrm{T}}$ are significantly and negatively correlated with their pre-addition values. Specifically, the correlation between $\Delta g$ and pre- $g$ is about $-46 \%$ and the correlation between $\Delta \mathrm{PI}_{\mathrm{T}}$ and pre- $\mathrm{PI}_{\mathrm{T}}$ is approximately $-69 \%$. These negative correlations are consistent with the view that greater changes in market quality are associated with firms that have lower market quality in the pre-addition period. Thus, the stocks with lower market quality in the pre-addition period benefit more from joining the index. The correlation between the changes in market quality and the changes in explanatory variables vary substantially. $\triangle P I$ is significantly positively correlated with $\triangle V A R$, $\triangle N T$ and $\triangle B T M V$, indicating that greater price inefficiency is associated with higher idiosyncratic risk, higher number of trades and higher book-to-market value.

\section{[Insert Table 6 about here]}

With regard to other correlations in Table 6, in some cases the correlations between the explanatory variables are fairly high. For example, the correlation between $\triangle M V$ and $B T M V$, $\Delta$ Lexix/Nexis and $\Delta N T$ are $32 \%, 42.8 \%$, respectively. To avoid multicollinearity problems, we avoid including highly correlated variables in the same regression.

\subsubsection{Regression results}

Table 7 reports the cross-sectional regression results. Panels A and B report the results from the changes in the speed of price adjustment $(\Delta g)$ and price inefficiency $\left(\Delta \mathrm{PI}_{\mathrm{T}}\right)$, respectively. We include different proxies related to stocks' characteristics as each alternative proxy may only capture a certain aspect of liquidity, information environment and risk.

Panel A shows that $\Delta g$ is negatively related to pre- $g$ across all models. This finding indicates that stocks with lower market quality in the pre-addition period benefit more from joining the index. The coefficient on $\triangle B T M V$ (in Model 2) is positive and significant at the $10 \%$ level, indicating that increasing $B T M V$ stocks react more aggressively to information than decreasing BTMV stocks. Similarly, the significantly positive coefficient on $\Delta N T$ (in Model 1) reflects the positive association between the price adjustment parameter and trading frequency. The negative coefficient on $\Delta$ Ask-Bid (in Model 3) indicates 
that prices reflect information faster when transaction costs are reducing. This evidence is consistent with Mech (1993), who shows that price-adjustment delays occur because of the high bid-ask spread. The coefficients on $\triangle M V, \triangle V O, \triangle$ Zeros, $\triangle A m i h u d, \triangle V A R$ and $\triangle$ Lexis/Nexis are not statistically significant.

\section{[Insert Table 7 about here]}

We repeat our analysis using $\Delta \mathrm{PI}_{\mathrm{T}}$ as the dependent variable and report the results in Panel $\mathrm{B}$ of Table 7. The coefficient on pre- $\mathrm{PI}_{\mathrm{T}}$ is negative and significant across all models, indicating that less efficiency priced stocks benefit more from the price noise reduction after joining the index. The coefficient on $\triangle B T M V$ (in Model 5) is positive and significant at the $1 \%$ level, indicating that high $B T M V$ are more likely to be mispriced. This evidence is consistent with several studies in the literature, including Chan and Faff (2005), Chen and Zhang (1998) and Lu and Hwang (2007). The coefficient on $\triangle V A R$ (in Model 6) is also positive and significant at the $1 \%$ level, implying that the price discovery process of stocks with increasing idiosyncratic risk is noisier. This evidence is consistent with Kelly (2005) who reports a positive association between idiosyncratic risk and noise trading. The significantly positive coefficient associated with $\triangle A s k$-Bid (in Model 6) indicates that pricing inefficiency is positively related to transaction costs. Ali et al. (2003) also show positive association between transaction costs and the level of mispricing. The variables $\Delta M V, \Delta V O, \Delta N T, \Delta A m i h u d, \Delta$ Zeros and $\Delta$ Lexis/Nexis do not explain the amount of noise in the stock prices.

In brief, the cross-sectional-regressions show that the change in market quality is explained, at least partly, by the pre-addition market quality and the contemporaneous changes in information environment, idiosyncratic risk, liquidity and book-to-market value.

\section{Conclusion}

The Kalman filter technique allows us to estimate the stock's price adjustment parameter $(g)$ and its intrinsic value $\left(v_{t}\right)$ from the partial adjustment with noise model of Amihud and Mendelson (1987). These parameters are then used to compute the pricing inefficiency index, which measures the extent to which transaction prices deviate from their intrinsic value. The partial adjustment coefficient and price inefficiency metrics are used to examine the impact of the addition to (deletion from) the FTSE 100 index on informational efficiency. We also use a control sample to ensure that our results are not driven by other market index factors.

Our results show that market quality improves after additions, but does not deteriorate following deletions. This asymmetric effect can be attributed, at least partly, to idiosyncratic risk, liquidity and other fundamental characteristics, which improve following additions, but do not change after deletions. The cross-sectional analysis also indicates that stocks with low pre-addition market quality benefit more from being members of the index. This evidence is consistent with Roll et al.'s (2009) findings that information 
production following option listing is larger in stocks where information asymmetries are greater and where investment analysis produces comparatively less public information.

\section{Reference}

Ali, A., Hwang, L.S., Trombley, M.A. (2003) Arbitrage risk and the book-to-market anomaly. Journal of Financial Economics, 69 (2), 355-373.

Amihud, Y., Mendelson, H. (1986) Asset pricing and the bid-ask spread. Journal of Financial Economics, 1, 17

Amihud, Y., Mendelson, H. (1987) Trading Mechanisms and Stock Returns: An Empirical Investigation. The Journal of Finance, 42 (3), 533-553.

Bacidore, J. M. (1997) The Impact of Decimalization on Market Quality: An Empirical Investigation of the Toronto Stock Exchange. Journal of Financial Intermediation, 6 (2), 92-120.

Bhagat, S., Brickley, J.A., Lease, R.C. (1985) Incentive effects of stock purchase plans. Journal of Financial Economics, 14 (2), 195-215.

Bhushan, R. (1989) Firm characteristics and analyst following. Journal of Accounting and Economics, 11 (2-3), 255-274.

Black, F. (1986) Noise. The Journal of Finance, 41 (3), 529-543.

Brennan, M.J., Jegadeesh, N., Swaminathan, B. (1993) Investment analysis and the adjustment of stock prices to common information. Review of Financial Studies, 6 (4), 799-824.

Brooks, R. D., Faff, R.W., McKenzie, M.D. (1998) Time Varying Beta Risk of Australian Industry Portfolios: A Comparison of Modelling Techniques. Australian Journal of Management, 23 (1), $1-22$.

Cai, J. (2007) What's in the News? Information Content of S\&P 500 Additions. Financial Management, 36 (3), 113-124.

Chakrabarti, R. (2002) Market Reaction to Addition of Indian Stocks to the MSCI Index. Money and Finance, 2 (11), 23. 
Chakrabarti, R., Huang, W., Jayaraman, N., Lee, J. Price and volume effects of changes in MSCI indices nature and causes. Journal of Banking \& Finance, 29 (5), 1237-1264.

Chan, H.W., FAff, R.W. (2005) Asset Pricing and the Illiquidity Premium. Financial Review, 40 (4), 429 458.

Chelley-Steeley, P. (2003) The trading mechanism, cross listed stocks: a comparison of the Paris Bourse and SEAQ-International. Journal of International Financial Markets, Institutions and Money, 13 (4), 401-417.

Chelley-Steeley, P. L. (2008) Market quality changes in the London Stock Market. Journal of Banking \& Finance, 32 (10), 2248-2253.

Chen, H., Noronha, G., Singal, V. (2004) The price response to S\&P 500 index additions and deletions: evidence of asymmetry and a new explanation. Journal of Finance, 59, No. 4 1901-29, August 2004.

Chen, H., Noronha, G., Singal, V. (2006) S\&P 500 index changes and investor awarness. Journal of investment management 4(2), 23-37.

Chen, N.F., Zhang, F. (1998) Risk and Return of Value Stocks. Journal of Business, 71 (4).

Chiang, T. C., Nelling, E., Tan, L. (2008) The speed of adjustment to information: Evidence from the Chinese stock market. International Review of Economics \& Finance, 17 (2), 216-229.

Chordia, T., Swaminathan, B. (2000) Trading Volume and Cross-Autocorrelations in Stock Returns. The Journal of Finance, 55 (2), 913-935.

Chung, R., Kryzanowski, L. (1998) Are the market effects associated with revisions to the TSE300 Index robust? Multinational Finance Journal, 2 (1), 1-36.

Damodaran, A. (1993) A Simple Measure of Price Adjustment Coefficients. The Journal of Finance, 48 (1), 387-400.

Daniel, P., Gerard, G. (2007) The index effect: an investigation of the price, volume and trading effects surrounding changes to the S\&P Australian indices. Working Paper. Deakin University

De Long, J. B., Shleifer, A., Summers, L.H., Waldmann, R.J. (1990) Noise Trader Risk in Financial Markets. The Journal of Political Economy, 98 (4), 703-738.

Denis, D. K., Macconnell, J.J., Ovtchinnikov, A.V., Yu, Y. (2003) S\&P 500 index additions and earnings expectations. Journal of Finance, 58 (5), 1821-40.

Dhillion, U., Johnson, H. (1991) Changes in the Standard and Poor's 500 List. The Journal of Business, 64 (1), 75-85.

Dunis, C. L., Morrison, V. (2007) The Economic Value of Advanced Time Series Methods for Modelling and Trading 10-year Government Bonds. The European Journal of Finance, 13 (4), 333 - 352.

Durnev, A., Morck, R., Yeung, B., Zarowin, P. (2003) Does Greater Firm-Specific Return Variation Mean More or Less Informed Stock Pricing? Journal of Accounting Research, 41 (5), 797-836.

Easley, D., O'Hara, M. (1987) Price, trade size, and information in securities markets. Journal of Financial Economics, 19 (1), 69-90.

Elayan, F. A., Li, W., Pinfold, J.F. (2000) Price Effects of Changes to the Composition of New Zealand Share Indices. SSRN eLibrary.

FAff, R.W., Hillier, D., Hillier, J. (2000) Time Varying Beta Risk: An Analysis of Alternative Modelling Techniques. Journal of Business Finance \& Accounting, 27 (5-6), 523-554.

Fama, E. F., French, K. R. (1992) The Cross-Section of Expected Stock Returns. The Journal of Finance, 47 (2), 427-465.

Grossman, S. J., Merton, H. M. (1988) Liquidity and Market Structure. The Journal of Finance, 43 (3), 617-633.

Hacibedel, B. (2008) Why do index changes have price effects? University of Oxford.

Harris, L., Gurel, E. (1986) Price and volume effects associated with changes in the S\&P 500 list: new evidence for the existence of price pressures. Journal of Finance, 41 815-29 September 1986.

Harvey, A. C. (1991) Forecasting, Structural Time Series and the Kalman Filter. Cambridge: Cambridge University Press.

Hasbrouck, J. (1993) Assessing the Quality of a Security Market: A New Approach to Transaction- Cost Measurement. The Review of Financial Studies, 6 (1), 191-212.

Hegde, S.P., Mcdermott, J. B. (2003) The liquidity effects of revisions to the S\&P 500 index: an empirical analysis. Journal of Financial Markets, 6 (3), 413-459. 
Huang, R.D., Masulis, R. W. (2003) Trading activity and stock price volatility: evidence from the London Stock Exchange. Journal of Empirical Finance, 10 (3), 249-269.

Jennings, R., Starks, L. (1985) Information Content and the Speed of Stock Price Adjustment. Journal of Accounting Research, 23 (1), 336-350.

Kelly, P. J. (2005) Information Efficiency and Firm-Specific Return Variation. Arizona State University. Arizona State University, Arizona State University.

Lesmond, D.A., Ogden, J.P., Trzcinka, C.A. (1999) A New Estimate of Transaction Costs. The Review of Financial Studies, 12 (5), 1113-1141.

Liu, S. (2009) Index membership and predictability of stock returns: The case of the Nikkei 225. PacificBasin Finance Journal, 17 (3), 338-351.

Lu, C., Hwang, S. (2007) Cross-Sectional Stock Returns in the UK Market: The Role of Liquidity Risk. FORECASTING EXPECTED RETURNS, Butterworth-Heinemann, Forthcoming.

Lynch, A.W., Mendenhall, R.R. (1997) New evidence on stock price effects associated with changes in the S \& P 500 index. Journal of Business, 70 351-83, July 1997.

Madhavan, A., Porter, D., Weaver, D. (2005) Should securities markets be transparent? Journal of Financial Markets, 8 (3), 265-287.

Mase, B. (2007) The Impact of Changes in the FTSE 100 Index. Financial Review, 42 (3), 461-484.

Mazouz, K., Saadouni, B. (2007) New evidence on the price and liquidity effects of the FTSE 100 index revisions. International Review of Financial Analysis, 16 (3), 223-241.

Mech, T.S. (1993) Portfolio return autocorrelation. Journal of Financial Economics, 34 (3), 307-344.

Pruitt, S.W., Wei, K.C.J. (1989) Institutional Ownership and Changes in the S\&P 500. The Journal of Finance, 44 (2), 509-513.

Rigamonti, S., Barontini, R. (2000) Stock Index Futures and the Effect on Cash Market in Italy: Evidence from Changes in Indexes' Composition. SSRN eLibrary.

Roll, R., Schwartz, E., Subrahmanyam, A. (2009) Options trading activity and firm valuation. Journal of Financial Economics, 94 (3), 345-360.

Shankar, S.G., Miller, J. M. (2006) Market Reaction to Changes in the S\&P SmallCap 600 Index. Financial Review, 41 (3), 339-360.

Shleifer, A. (1986) Do demand curves for stocks slope down? Journal of Finance, 41 579-90 July 1986.

Hauser, S., Levy, A., Yaari, U. (2001) Trading frequency and the efficiency of price discovery in a nondealer market. European Journal of Finance, 7 (3), 187-197.

Sofianos, G. (1993) Index Arbitrage Profitability. Journal of Derivatives, 1 (6), 20.

Sui, L. (2003) The Addition and Deletion Effects of the Standard \& Poor's 500 Index and Its Dynamic Evolvement from 1990 to 2002: Demand Curves, Market Efficiency, Information, Volume and Return. SSRN eLibrary.

Vespro, C. (2006). Stock price and volume effects associated with compositional changes in European stock indices. European Financial Management Journal, 12(1), 103-127. 
Table 1: The yearly distribution of the sample of additions to and deletions from the FTSE 100 index

\begin{tabular}{ccc}
\hline Year & The sample of additions & The sample of deletions \\
\hline 1984 & 4 & 8 \\
1985 & 9 & 9 \\
1986 & 13 & 7 \\
1987 & 5 & 7 \\
1988 & 8 & 5 \\
1989 & 8 & 8 \\
1990 & 3 & 6 \\
1991 & 7 & 10 \\
1992 & 15 & 17 \\
1993 & 9 & 11 \\
1994 & 3 & 4 \\
1995 & 11 & 8 \\
1996 & 5 & 8 \\
1997 & 7 & 9 \\
1998 & 7 & 13 \\
1999 & 8 & 9 \\
2000 & 17 & 18 \\
2001 & 12 & 9 \\
2002 & 12 & 4 \\
2003 & 5 & 6 \\
2004 & 7 & 4 \\
2005 & 6 & 5 \\
2006 & 7 & 2 \\
2007 & 9 & 11 \\
2008 & 12 & 10 \\
2009 & 3 & 2 \\
Total & 212 & 210 \\
\hline & &
\end{tabular}


Table 2

Descriptive statistics

This table reports the means and medians of firm characteristics over the [-261, -30] window around index revisions. Firm size ( $M V)$ is the average market capitalization (in millions of pounds). Book to market value $(B T M V)$ is the ratio of book value to market value. Trading volume $(V O)$ is the turnover by volume. Number of trades $(N T)$ is the average number of daily transactions for a particular stock. Ask minus bid (Ask-bid) is the average difference between ask and bid price. Amihud is the average ratio of the daily absolute return to the pound trading volume on that day. Zeros is the number of zeros in the daily return series in the pre-index revision period. The control is constructed by matching each event stock with a non-event stock with the closest pre-revision market capitalization. The asterisks ${ }^{* * * *}{ }^{* *}$ and ${ }^{*}$ indicate significance at the two-sided $1 \%, 5 \%$ and $10 \%$ levels, respectively.

\begin{tabular}{|c|c|c|c|c|c|c|}
\hline \multicolumn{7}{|c|}{ Panel A: The summary statistics for the additions and their control sample } \\
\hline & \multicolumn{2}{|c|}{ Additions } & \multicolumn{2}{|c|}{ Control } & \multicolumn{2}{|c|}{ The difference between Additions and Control } \\
\hline & Mean & Median & Mean & Median & t-Stat & Mann Whitney \\
\hline $\operatorname{MV}\left(10^{3}\right)$ & 1,658 & 1,703 & 1,952 & 1,663 & $2.598^{* * *}$ & -1.348 \\
\hline BTMV & 0.578 & 0.480 & 0.615 & 0.535 & 0.724 & -0.639 \\
\hline $\mathrm{VO}\left(10^{3)}\right.$ & 3,691 & 1,888 & 3,371 & 1,735 & -0.580 & -1.271 \\
\hline NT & 461 & 135 & 448 & 113 & -0.162 & -0.329 \\
\hline ASK_Bid & 3.542 & 2.830 & 4.060 & 2.960 & 1.339 & -1.120 \\
\hline Amihud $\left(10^{6}{ }^{6}\right.$ & 9.175 & 3.320 & 5.736 & 3.270 & $1.193^{*}$ & -0.322 \\
\hline Zeros & 29 & 22 & 29 & 23 & -0.032 & -0.048 \\
\hline
\end{tabular}

Panel B: The summary statistics for the deletions and their control sample

\begin{tabular}{|c|c|c|c|c|c|c|}
\hline & \multicolumn{2}{|c|}{ Deletions } & \multicolumn{2}{|c|}{ Control } & \multicolumn{2}{|c|}{ The difference between Deletions and Control } \\
\hline & Mean & Median & Mean & Median & t-Stat & Mann Whitney \\
\hline $\operatorname{MV}\left(10^{3)}\right.$ & 2,070 & 1,934 & 1,539 & 1,301 & $3.685^{* * *}$ & $-4.570^{* * *}$ \\
\hline BTMV & 0.544 & 0.485 & 0.595 & 0.480 & -1.192 & -0.541 \\
\hline $\mathrm{VO}\left(10^{3)}\right.$ & 4,225 & 2,226 & 2,463 & 1,333 & $3.496^{* * *}$ & $-4.368^{* * *}$ \\
\hline NT & 503 & 121 & 279 & 48 & $3.013^{* * *}$ & $-4.507^{* * *}$ \\
\hline ASK_Bid & 3.912 & 2.985 & 3.895 & 3.085 & 0.895 & -0.140 \\
\hline Amihud(10- $\left.{ }^{6}\right)$ & 4.189 & 2.615 & 24.200 & 4.760 & $-1.671^{*}$ & $-5.275^{* * *}$ \\
\hline Zeros & 28 & 22 & 38 & 31 & $-3.744^{* * *}$ & $-4.269^{* * *}$ \\
\hline
\end{tabular}




\section{Table 3}

Summary statistics for the explanatory variables.

Cross-sectional means and medians of firm size $(M V)$, book to market value $(B T M V)$, the variance in residuals $(V A R)$, trading volume $(V O)$, number of trades $(N T)$, Ask minus bid (Ask-Bid), illiquidity (Amihud), the number of zero return (Zeros), and media coverage (Lexis/Nexis) are computed over the [-261, -30] and [+30, +260] windows around additions. This study uses trading volume (VO), number of trades (NT), Ask minus bid (Ask-Bid), illiquidity (Amihud), and the (Zeros) as proxies for liquidity. VO is turnover by volume. NT is the number of daily transactions for a particular stock. Amihud (2002) defines illiquidity as the average ratio of the daily absolute return to the sterling trading volume on that day. The common factor risks and idiosyncratic risk are identified by the variance of residuals ( $V A R)$, market capitalisation $(M V)$ and book to market value (BTMV). We define the idiosyncratic risk of a stock $i$, or $V A R_{i}$, as the variance of the residuals resulting from regressing stock returns on the returns of the market portfolio. The change in information environment is measured by Lexis/Nexis. The paired t-test and Wilcoxon Signed Rank test are then used to judge the statistical significance of the changes, across pre- and post-addition periods, in the different liquidity proxies. The ${ }^{* * *},{ }^{* *},{ }^{*}$ indicate significance at the two-sided $1 \%, 5 \%$, and $10 \%$ levels respectively.

\begin{tabular}{|c|c|c|c|c|c|c|c|c|}
\hline \multicolumn{9}{|c|}{ Changes inthe explanatory variables following additions (deletions) } \\
\hline & \multicolumn{4}{|c|}{ Change following additions } & \multicolumn{4}{|c|}{ Change following deletions } \\
\hline & Mean & Median & t-test & Wilcoxon & Mean & Median & t-test & Wilcoxon \\
\hline & 517 & 269 & $-8.466^{\star \star \star}$ & $-8.339^{\star \star \star}$ & -458 & -512 & $4.795^{\star \star \star}$ & $-5.638^{\star * \star}$ \\
\hline \multicolumn{9}{|l|}{ MV } \\
\hline & -0.081 & -0.025 & $4.165^{\star \star \star}$ & $-5.988^{* * *}$ & 0.269 & 0.090 & -1.396 & $-5.206^{\star * *}$ \\
\hline BTMV & & & & & & & & \\
\hline $\operatorname{VAR}\left(\times 10^{3}\right)$ & -0.025 & -0.088 & -0.283 & -1.440 & -2.098 & -0.140 & $2.025^{\star *}$ & -1.416 \\
\hline \multirow[t]{2}{*}{$V O\left(\times 10^{3}\right)$} & 236 & 563 & -1.390 & $-4.113^{\star \star \star}$ & 335 & 179 & -1.530 & -1.326 \\
\hline & 201 & 145 & $--5.837^{* * *}$ & $-8.781^{* * *}$ & -18 & -4 & 0.592 & -0.812 \\
\hline \multicolumn{9}{|l|}{$N T$} \\
\hline & -0.122 & 0.01 & 0.4287 & $-1.803^{\star}$ & -0.681 & -0.130 & 1.440 & $-2.259^{\star *}$ \\
\hline \multicolumn{9}{|l|}{ Ask_Bid } \\
\hline \multirow[t]{2}{*}{ Amihud $\left(\times 10^{6}\right)$} & -1.528 & -1.230 & $1.929^{\star \star}$ & $-6.574^{\star * *}$ & 10.916 & 1.365 & -1.001 & $-5.540^{\star \star *}$ \\
\hline & -4 & -5 & $2.616^{\star \star \star}$ & $-6.137^{\star \star \star}$ & 9 & 4 & $-3.785^{\star \star \star}$ & $-3.795^{\star \star \star}$ \\
\hline \multicolumn{9}{|l|}{ Zeros } \\
\hline & 73 & 21 & $-5.386^{\star * *}$ & $-11.832^{\star * *}$ & -9 & -14 & 0.654 & 0.512 \\
\hline
\end{tabular}




\section{Table 4}

\section{Estimation of $\mathrm{g}$ and $\mathrm{PI}_{\mathrm{T}}$ over pre-and post- addition periods for addition and control}

In this table we presents market quality estimates for the pre- and post-addition period that have been obtained from the Kalman filter estimates of the Amihud and Mendelson (1987) model in the pre- and post-index revision periods. $g$ is a partial adjustment coefficient and $\mathrm{PI}_{\mathrm{T}}$ is the pricing inefficiency parameter of Chelley-Steeley (2008). The control sample is constructed by matching each event stock with a non-event stock that has the closest market capitalization at one month prior to the event date. The ${ }^{* *}$ and ${ }^{*}$ indicate significance at the two-sided $5 \%$ and $10 \%$ levels, respectively. \% increase in adjustment reports the percentage of the sample that experiences a rise in the partial adjustment parameter in the post-addition period, \% decline in inefficiency is the percentage of the sample that experiences a decline in pricing inefficiency in the post-addition period. The $\mathrm{PI}_{\mathrm{T}}$ variable is multiplied by 1000 following Chelley-Steeley (2003)

\begin{tabular}{|c|c|c|c|c|c|c|c|}
\hline \multicolumn{8}{|c|}{ Panel A: Estimation of $\mathrm{g}$ for additions and control } \\
\hline & \multicolumn{2}{|c|}{ Pre } & \multicolumn{2}{|c|}{ Post } & \multicolumn{3}{|c|}{ pre versus post } \\
\hline & Mean & Median & Mean & Median & $\% \mathrm{~g}$ increase & t-stat & Wilcoxon \\
\hline Additions & 0.924 & 0.907 & 0.966 & 0.959 & $63 \%$ & $-4.479^{* * *}$ & $-4.097^{* * *}$ \\
\hline Control & 0.950 & 0.946 & 0.959 & 0.961 & $51 \%$ & -0.890 & -0.525 \\
\hline \multicolumn{8}{|c|}{ Panel B: Estimation of $\mathrm{PI}_{\mathrm{T}}$ for additions and control } \\
\hline \multicolumn{8}{|c|}{ ( } \\
\hline & Pre & & Post & & pre versus post & & \\
\hline & Mean & Median & Mean & Median & $\%$ PI decrease & t-stat & Wilcoxon \\
\hline Additions & 1.988 & 1.613 & 1.705 & 1.316 & $56 \%$ & $1.842^{*}$ & $-1.830 *$ \\
\hline Control & 1.533 & 1.168 & 1.613 & 1.167 & $52 \%$ & -0.467 & -0.824 \\
\hline
\end{tabular}




\section{Table5}

The estimation of $g$ and PI over pre-and post- deletions periods for deletion and control

In this table we presents market quality estimates for the pre- and post-addition period that have been obtained from the Kalman filter estimates of Amihud and Mendelson (1987) model in the pre- and post-index revision periods. $g$ is a partial adjustment coefficient and PI is the pricing inefficiency parameter of Chelley-Steeley (2008). The control sample is constructed by matching each event stock with a non-event stock with the closest market capitalization at one month prior the event date. The " and "indicate significance at $5 \%$ and $10 \%$ levels, respectively. \% increase in adjustment reports the percentage of the sample that experiences a rise in the partial adjustment parameter in the post-addition period, \% decline in inefficiency is the percentage of the sample that experiences a decline in pricing inefficiency in the post-addition period. The PI is multiplied by 1000 as in the Chelley-Steeley (2003).

\section{Panel A the estimation of $\mathrm{g}$ for deletions and control}

\begin{tabular}{|c|c|c|c|c|c|c|c|}
\hline \multicolumn{8}{|c|}{ Deletions } \\
\hline & \multicolumn{2}{|c|}{ Pre } & \multicolumn{2}{|c|}{ Post } & \multicolumn{3}{|c|}{ pre versus post } \\
\hline & Mean & Median & Mean & Median & $\%$ g increase & t-stat & Wilcoxon \\
\hline Deletions & 0.948 & 0.936 & 0.939 & 0.935 & $46 \%$ & 1.141 & -0.859 \\
\hline Control & 0.918 & 0.905 & 0.936 & 0.934 & $53 \%$ & $-1.890^{*}$ & -1.077 \\
\hline
\end{tabular}

Panel B the estimation of PI for deletions and control

\begin{tabular}{|c|c|c|c|c|c|c|c|}
\hline \multicolumn{8}{|c|}{ Deletions } \\
\hline & \multicolumn{2}{|c|}{ Pre } & \multicolumn{2}{|c|}{ Post } & \multicolumn{3}{|c|}{ pre versus post } \\
\hline & Mean & Median & Mean & Median & $\%$ PI decrease & t-stat & Wilcoxon \\
\hline Deletions & 1.729 & 1.172 & 1.802 & 1.186 & $46 \%$ & -0.457 & -0.305 \\
\hline Control & 1.751 & 1.398 & 1.591 & 1.211 & $55 \%$ & 1.072 & $-1.651 *$ \\
\hline
\end{tabular}




\begin{tabular}{|c|c|c|c|c|c|c|c|c|c|c|c|c|}
\hline & Pre_PI ${ }_{\mathrm{T}}$ & Pre_g & $\Delta g$ & $\Delta P I$ & $\Delta M V$ & $\triangle B T M V$ & $\Delta V O$ & $\Delta N T$ & $\Delta$ Amihud & $\Delta$ Ask Bid & $\Delta$ Zero & $\triangle V A R$ \\
\hline Pre_g & $-.458^{\star \star}$ & & & & & & & & & & & \\
\hline$\Delta g$ & $.326^{\star *}$ & $-.460^{\star *}$ & & & & & & & & & & \\
\hline$\Delta \mathrm{PI}_{\mathrm{T}}$ & $-.690^{* *}$ & $.260^{\star *}$ & $-.395^{\star *}$ & & & & & & & & & \\
\hline$\Delta M V$ & .105 & -.125 & .045 & -.063 & & & & & & & & \\
\hline$\triangle B T M V$ & -.085 & .048 & .090 & $.315^{\star \star}$ & $-.323^{\star *}$ & & & & & & & \\
\hline$\Delta V O$ & -.015 & -.105 & .058 & .165 & -.033 & .098 & & & & & & \\
\hline$\Delta N T$ & $-.218^{\star *}$ & .134 & -.026 & $.265^{\star *}$ & .093 & $.285^{\star *}$ & .132 & & & & & \\
\hline$\Delta$ Amihud & -.071 & .040 & .041 & .098 & $-.177^{\star}$ & $.218^{\star \star}$ & -.042 & .077 & & & & \\
\hline$\triangle$ Ask-Bid & .105 & $-.334^{\star *}$ & .048 & -.004 & $.302^{* *}$ & -.015 & -.050 & -.055 & .007 & & & \\
\hline$\Delta$ Zero & .017 & .127 & -.089 & -.041 & $-.179^{\star}$ & .126 & .009 & .022 & .014 & .134 & & \\
\hline$\triangle V A R$ & .015 & -.035 & -.066 & $.211^{\star *}$ & .121 & $.201^{*}$ & .052 & $.310^{\star *}$ & -.032 & $.202^{*}$ & -.015 & \\
\hline$\Delta$ Lexis/Nexis & .020 & .058 & -.014 & -.023 & .053 & .114 & .065 & $.428^{\star *}$ & .065 & .089 & .054 & $.250^{* *}$ \\
\hline
\end{tabular}




\begin{tabular}{|c|c|c|c|c|c|c|}
\hline \multicolumn{7}{|c|}{ 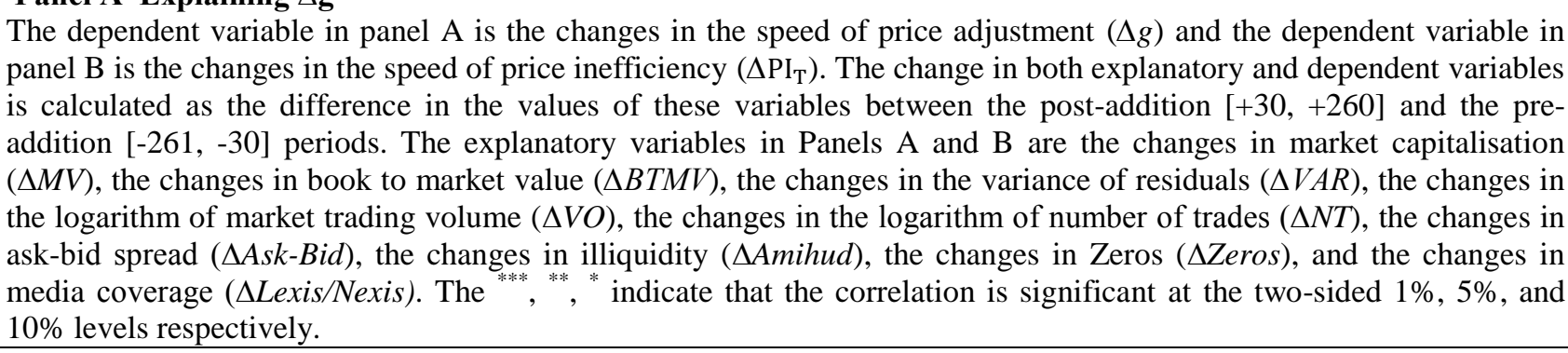 } \\
\hline \multicolumn{7}{|c|}{ Panel A The determinants of $\Delta g$} \\
\hline \multicolumn{3}{|c|}{ Explanatory Variables $\quad$ Model 1} & \multicolumn{2}{|c|}{ Model 2 } & \multicolumn{2}{|c|}{ Model 3} \\
\hline & Coef. & t.stat & Coef. & t.stat & Coef. & t.stat \\
\hline Intercept & 0.408 & $6.646^{* * *}$ & 0.452 & $7.543^{* * * *}$ & 0.484 & $7.498^{* * *}$ \\
\hline Pre_g & -0.427 & $-6.736^{* * *}$ & -0.443 & $-6.967^{* * *}$ & -0.481 & $-7.026^{* * *}$ \\
\hline$\Delta M V$ & -1.070 & -1.007 & & & & \\
\hline$B T M V$ & & & 0.065 & $1.886^{*}$ & & \\
\hline$\triangle V A R$ & & & 0.000 & -1.585 & & \\
\hline$\Delta V O$ & -0.014 & -1.361 & & & -0.012 & -1.122 \\
\hline$\Delta N T$ & 0.058 & $2.910^{* * *}$ & & & & \\
\hline$\Delta A s k \_B i d$ & & & & & -0.010 & $-1.772 *$ \\
\hline$\Delta$ Amihud & & & 3.950 & 0.433 & 7.279 & 0.804 \\
\hline $\begin{array}{l}\Delta \text { Zeros } \\
\Delta \text { Lexis/Nexis }\end{array}$ & 0.000 & -0.447 & 0.000 & -0.715 & $\begin{array}{l}0.000 \\
2.179\end{array}$ & $\begin{array}{l}-0.461 \\
0.369\end{array}$ \\
\hline Adjusted R2 & 0.230 & & 0.216 & & 0.205 & \\
\hline F-value & 11.70 & & 10.87 & & 8.70 & \\
\hline \multicolumn{7}{|c|}{ Panel B The determinants of $\Delta \mathrm{PI}_{\mathrm{T}}$} \\
\hline & \multicolumn{2}{|c|}{ Model 4} & \multicolumn{2}{|c|}{ Model 5} & \multicolumn{2}{|c|}{$\begin{array}{l}\text { Model } 6 \\
\end{array}$} \\
\hline & Coef. & t.stat & Coef. & t.stat & Coef. & t.stat \\
\hline Intercept & 0.001 & $5.289^{* * * * *}$ & 0.001 & $8.783^{* * * *}$ & 0.001 & $7.274^{* * * *}$ \\
\hline Pre_PI & -0.853 & $-12.846^{* * *}$ & -0.826 & $-13.487^{* * *}$ & -0.858 & $-12.954^{* * *}$ \\
\hline$\Delta M V$ & -5.164 & -0.354 & & & & \\
\hline$B T M V$ & & & 0.002 & $4.137^{* * * * *}$ & & \\
\hline$\triangle V A R$ & & & 6.843 & $3.47^{* * * *}$ & & \\
\hline$\Delta V O$ & 0.000 & $1.712^{*}$ & & & 0.000 & $2.635 * * *$ \\
\hline$\Delta N T$ & 0.000 & 1.543 & & & & \\
\hline$\Delta A s k \_B i d$ & & & & & 0.000 & $1.955^{* * *}$ \\
\hline$\Delta$ Amihud & & & 3.119 & 0.271 & 1.265 & 1.036 \\
\hline$\Delta$ Zeros & 1.133 & 0.130 & -8.009 & -1.038 & -6.434 & -0.076 \\
\hline$\Delta$ Lexis/Nexis & & & & & -3.016 & -0.380 \\
\hline Adjusted R2 & 0.483 & & 0.559 & & 0.487 & \\
\hline F-value & 34.43 & & 46.31 & & 29.36 & \\
\hline
\end{tabular}


